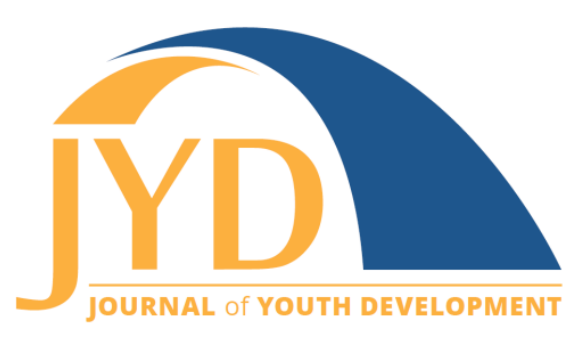

http://jyd. pitt. edu/ | Vol. 14 Issue 4 DOI 10.5195/jyd.2019.738 | ISSN 2325-4017 (online)

\title{
STEM Professional Development for Youth Workers: Results of a Triangulated Study
}

\author{
Melissa Pearman Fenton \\ University of Florida \\ mfenton1@ufl.edu \\ Leslie Hawley \\ Susan Thompson Buffett Foundation \\ Irhawley05@gmail.com \\ Saundra Wever Frerichs \\ University of Nebraska-Lincoln \\ sfrerichs3@unl.edu \\ Kathleen Lodl \\ University of Nebraska-Lincoln \\ klodl1@unl.edu
}

\begin{abstract}
To increase the quality of informal science, technology, engineering, and math (STEM) learning opportunities, many youth development professionals working in out-of-school time (OST) programs need professional development focused on facilitating these types of activities. Nebraska Extension developed an open-access repository of resources that support an ongoing, blended approach to STEM professional development for youth workers. The current study evaluated the impact on staff, programs, and youth achieved by implementing Click2Science resources in sites at a large youth serving organization. Data sources included site or program director/coordinator and frontline staff perceptions about their experiences during the professional development events, observations of staff facilitating STEM learning with youth, and youth interest in STEM. Findings demonstrated an increase in STEM program quality, as measured by the Dimensions of Success (DoS) Observational Tool (n.d.). Site or program director/coordinators and frontline staff found the professional development eye-opening and user friendly, and noted increased youth engagement following the intervention. Youth reported positive perceptions of STEM learning experiences. Triangulation of these three sources confirmed the promising utility and effectiveness of this professional development approach. Further research is needed to extend
\end{abstract}

(c) $\mathbf{E Y}$ New articles in this journal are licensed under a Creative Commons Attribution 4.0 License. This journal is published by the University Library System, University of Pittsburgh and is cosponsored by the University of Pittsburgh Press. The Journal of Youth Development is the official peer-reviewed publication of the National Association of Extension 4-H Agents and the National AfterSchool Association. 


\section{STEM Professional Development}

the preliminary findings and support the case for increased investment in STEM professional development for youth development professionals.

Key words: professional development, STEM pedagogy, triangulated evaluation, youth worker skills

Out-of-school time (OST) programs that meet after school, on the weekends, or during the summer provide opportunities for youth to experience hands-on, materials-based investigations in an exploratory, supportive, flexible setting (Walker, Wahl, \& Rivas, 2005). Furtak, Seidel, Iverson, and Briggs (2012) found that youth exhibited more interest in STEM and better STEM learning outcomes after experiencing the type of investigations present in OST programs. These same programs can prepare more diverse youth to be interested in STEM, succeed in formal STEM courses, and pursue STEM career fields (Krishnamurthi \& Bevan, 2017). There is a growing need for STEM professionals (Fayer, Lacey, \& Watson, 2017) and these opportunities have the potential to fill the STEM career pipeline with a diverse workforce (National Research Council [NRC], 2015).

In 2014, 10.2 million children participated in an after-school program (Afterschool Alliance, 2014), interacting with an estimated 680,000 staff. Seven million of these children had access to after-school STEM learning experiences (Afterschool Alliance, 2015) facilitated by adults with a variety of experience levels, education, and content expertise (Nee, Howe, Schmidt, \& Cole, 2006; Yohalem \& Pittman, 2006). Staff capacity, in particular, was reported as a barrier to providing high quality STEM programs in OST settings (Afterschool Alliance, 2010; Chun \& Harris, 2011). Lack of staff expertise and comfort with science concepts, in addition to lack of access to STEM-specific training leave some OST programs reluctant to offer STEM programs to youth (Freeman, Dorph, \& Chi, 2009; Walker et al., 2005). The after-school workforce needs access to STEM specific professional development as a way to improve STEM programming (Krishnamurthi \& Bevan, 2017; Krishnamurthi \& Sankar, 2012). Impactful professional development will help OST staff understand the skills they already possess, how to apply these skills to science activities, and help staff build and develop their expertise in science processes (NRC, 2015).

In one of the first cases to link STEM professional development for OST staff to youth outcomes, Vandell, Simzar, O'Cadiz, and Hall (2016) found that staff who were exposed to more professional development experiences reported increased efficacy in their ability to lead STEM learning experiences and stronger beliefs about the value of STEM learning. In turn, these staff also reported increased student engagement in STEM learning, which predicted relative gains in 


\section{STEM Professional Development}

youth work habits, math efficacy, science efficacy, social competency, and science interest over the school year (Vandell et al., 2016). This study supports the positive impact that STEMspecific professional development can have on OST staff and subsequently, the youth they interact with in OST programs.

\section{Click2SciencePD}

To support the needs of the diverse OST field, an approach to professional development was conceptualized by Nebraska Extension to expand the capacity for organizations to implement STEM professional development. Nebraska Extension developed a website, click2sciencepd.org, to house professional development materials written specifically for trainers of youth development professionals, which focused on the skills staff need to facilitate high-quality STEM learning experiences with youth. The model leverages the use of digital technology with inperson support to provide a low-cost, flexible model of professional development. All materials on the Click2SciencePD website are free to download after registering for an account. The online, self-directed web lessons described in the professional development approach are accessed on a partner organization's learning management system, Penn State Extension's Better Kid Care, and completed for a small fee ( $\$ 5$ per lesson).

A key feature of the Click2SciencePD model is the goal of improving the instructional practices of OST staff and volunteers by focusing on developing pedagogical skills, one at a time, through a cycle of professional development experiences that are reinforced by the actual practices of their program. The instructional practices support strategies for high-quality STEM learning experiences in preparing for success in STEM, supporting youth development through STEM, and developing STEM practices and mindset. Each strategy area includes specific pedagogical skills that staff can implement in their practice to increase youth learning and engagement (see Table 1 for a list of the strategies and skills). Strategies for preparing for success in STEM help staff plan and organize learning experiences. Strategies for supporting youth development through STEM prepare staff to facilitate positive and engaging experiences that contribute to youth development. Strategies for developing STEM practices and mindset contribute to learning experiences that build practices and knowledge in science, technology, engineering and math. 
STEM Professional Development

Table 1. The Click2SciencePD Strategies and Skills

\begin{tabular}{|l|l|l|}
\hline $\begin{array}{l}\text { Preparing for } \\
\text { Success in STEM }\end{array}$ & $\begin{array}{l}\text { Supporting Youth Development } \\
\text { Through STEM }\end{array}$ & $\begin{array}{l}\text { Developing STEM } \\
\text { Practices and Mindset }\end{array}$ \\
\hline $\begin{array}{l}\text { Preparing STEM learning } \\
\text { opportunities }\end{array}$ & Managing groups during STEM \\
\hline $\begin{array}{l}\text { Creating STEM learning } \\
\text { environments }\end{array}$ & $\begin{array}{l}\text { Encouraging collaborative STEM } \\
\text { work }\end{array}$ & Making authentic assessments \\
\hline & $\begin{array}{l}\text { Facilitating inclusive learning } \\
\text { experiences }\end{array}$ & Modeling engineering practices \\
\hline & $\begin{array}{l}\text { Developing a STEM identity } \\
\text { Making connections to STEM } \\
\text { careers }\end{array}$ & $\begin{array}{l}\text { Supporting documentation of } \\
\text { STEM learning }\end{array}$ \\
\hline & $\begin{array}{l}\text { Connecting to prior knowledge \& } \\
\text { experiences }\end{array}$ & $\begin{array}{l}\text { Reflecting and processing } \\
\text { experiences }\end{array}$ \\
\hline & $\begin{array}{l}\text { Giving youth control } \\
\text { Modeling science practices }\end{array}$ \\
\hline
\end{tabular}

For example, the purpose of the skill, "asking purposeful questions" is for staff to use purposeful questioning and feedback to increase youth learning in STEM. When staff implement that skill in their facilitation of a learning experience, they use a mixture of open-ended questions, wait time, and small and whole-group discussion management techniques. They use appropriate probing, clarifying, or reflection questions to help youth process and explain their learning. This in turn, should deepen youths' understanding of the STEM concepts and help them develop critical thinking skills. The additional 15 pedagogical skills help staff support the new vision for science education in the United States (NRC, 2012).

\section{Professional Development Approach}

Research supports ongoing, professional development experiences that offer different types of opportunities for staff to build their skills (Garet, Porter, Desimone, Birman, \& Yoon, 2001; Guskey \& Yoon, 2009). The Click2SciencePD ongoing cycle of professional learning focuses on a particular skill, like asking purposeful questions, that is developed, over time through a series of blended learning experiences. The following professional development experiences are included in the model and visually displayed in Figure 1: 


\section{STEM Professional Development}

1. Staff complete an online, self-directed lesson to introduce the skill. (1-2 hours)

2. Staff attend in-person, experiential training. (1-2 hours)

3. Staff practice using the skill during OST programming with youth.

4. Staff attend in-person or virtual meeting. (15-45 minutes)

5. Staff practice using the skill during OST programming with youth.

6. Staff participate in one-on-one or small group coaching. (15-30 minutes)

7. Staff continue to practice applying the skill in their program.

Figure 1. The Click2SciencePD Professional Development Approach.

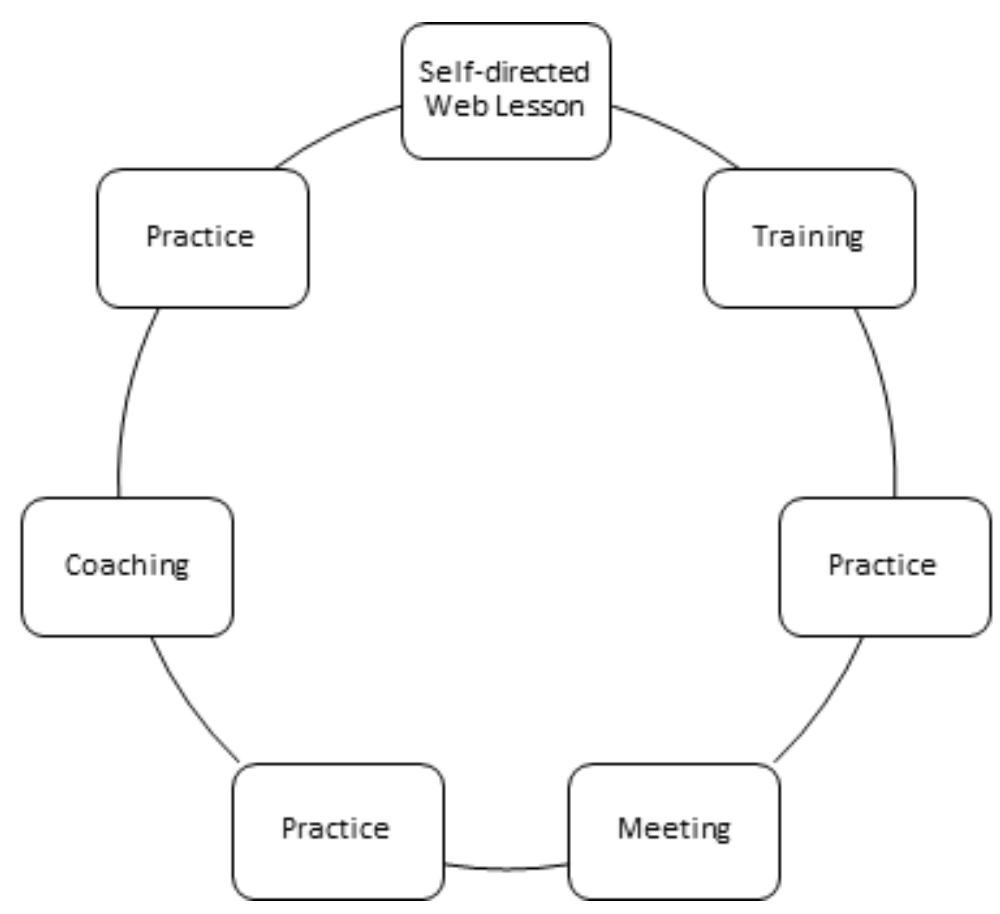

Youth worker turnover is high and recruiting high-quality staff is challenging (Yohalem, Pittman, \& Edwards, 2010). Professional development is often cited as a factor that supports staff retention and high-quality programming (Huang \& Cho, 2010). Nebraska Extension organized the professional development approach and materials to decrease the amount of preparation needed to provide high-quality professional development to staff. Guides for facilitating the training, meeting, and coaching described in the model are housed on the Click2SciencePD website and free to download. Each guide has step-by-step instructions for facilitating the professional development session that can be delivered as written or customized by the facilitator. Each guide also includes a list of supplies, handouts or activity instructions, links to 


\section{STEM Professional Development}

additional materials, and links to video-based learning modules. Video-based learning modules are included to spark conversation and feature real staff in real after-school programs. The videos are not intended to be best practice videos, but to show real practice and help staff see themselves as someone who can teach STEM. The model does not include directional arrows or sequential activities, rather it was designed so that a program could implement the learning experiences in their existing professional development structure. For example, programs could start with a meeting and use mostly meetings or trainings to provide professional development, instead of the web-lesson and coaching, if that fits best in their structure. Frerichs, Fenton, and Wingert (2018) provide a detailed conceptual description of the model for further reference.

The professional development approach is characterized by sustained and intensive focus on a single pedagogical skill, providing opportunities for active learning, the immediacy of application in practice, collective participation of program staff, and integration into the culture of the program. These characteristics are widely supported in educational research as key to effective professional development (Birman, Desimone, Porter, \& Garet, 2000; Garet et al., 2001; Guskey \& Yoon, 2009).

\section{Current Study}

The aim of this study was to triangulate data from site or program director/coordinators, frontline staff, and youth to evaluate the impact of Click2Science professional development on frontline staff's STEM facilitation practices in OST contexts. The main findings focused on changes in OST environments as facilitated by frontline staff. The researchers collected additional evidence from frontline staff and site or program director/coordinator focus groups/interviews, as well as youth survey data to triangulate evidence for the main results (see Figure 2 for a visual diagram of the triangulation strategy). 
Figure 2. Diagram of Triangulation Approach

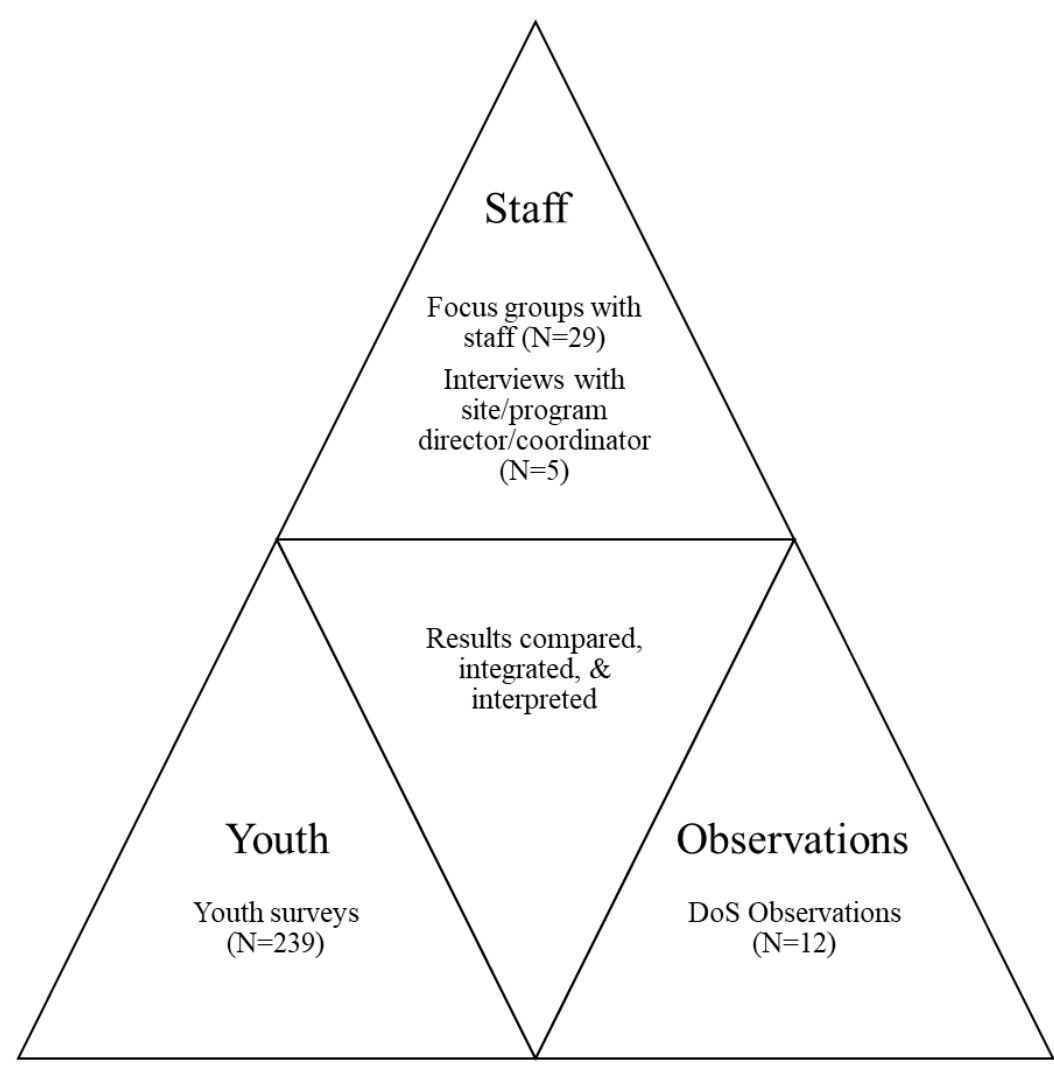

\section{Methods}

\section{Overall Training}

As part of an agreement between Nebraska Extension and the various locations that were provided training, at least two representatives were chosen from four program locations to serve on the evaluation leadership team. These site or program director/coordinators participated in a 21/2-day in-person training by Click2Science educators and participated in ongoing calls, virtual learning opportunities, observations, trainings, and coaching during the 2016-2017 school year resulting in a total of 40 hours of professional development. The goal of the professional development and ongoing support was to equip site or program director/coordinators with the tools necessary for them to train a group of frontline staff at their respective locations.

Trained site or program directors/coordinators from each program location selected 10 frontline staff to participate in professional development. Site or program directors/coordinators were responsible for delivering a minimum of 5 hours of professional development that included two 
STEM Professional Development

90-minute face-to-face, hands-on trainings; two 30-minute staff meetings; and two 30-minute coaching sessions. Staff were also expected to complete two 2-hour self-directed web lessons.

\section{Staff Observations}

\section{Participants}

Three frontline staff were randomly selected from four geographic locations in the study to participate in the pre- and post-training observations $(n=12)$. Geographic areas included urban and suburban locales in the South Central and Midwest regions of the country. Although 10 frontline staff participated in Click2Science professional development experiences at each location, it was not feasible to observe all 10 participants because most programs delivered content on the same day/time. Instead of watching all participants, three frontline staff from each location were randomly selected by the evaluator to serve as a sample of overall program quality.

\section{Observation Protocol}

A trained observer used the Dimensions of Success ([DoS]; Shah, Wylie, Gitomer, \& Noam, 2018) observation protocol (PEAR Institute, n.d.) to conduct observations at each location. A total of 12 dimensions in the DoS rubric are organized within four broad domains:

- Features of the learning environment

- Activity engagement

- STEM knowledge and practices

- Youth development in STEM

Each dimension was rated on a 4-point scale and points of evidence were provided to support each rating. All data collected using the DoS observation tool were collected by PEAR-certified observers.

\section{Procedures}

Selected staff from each location were observed facilitating a STEM activity at two points in time. The first observation occurred prior to the Click2Science professional development intervention and the second occurred after participants had concluded the majority of their professional development activities. For each observation, a certified DoS observer rated STEM program activities lasting from 30-60 minutes. 


\section{STEM Professional Development}

Observations were video recorded and backup video observations of one frontline staff member outside the randomly selected participants were also recorded. One of the original participants dropped out between the pre- and post-training observations, but there was a backup observation video available from the location. This one program was rated using a combination of live scoring and video for the pre-training rating and live scoring only for the post.

\section{Observation Results}

Although the DoS observation protocol includes four broad domains and a total of 12 dimensions, the results discussion focuses on the domain, STEM knowledge and practices, which includes three dimensions: (a) STEM content learning, (b) inquiry, and (c) reflection (PEAR Institute, n.d.; Shah, Wylie, Gitomer, \& Noam, 2014; Shah et al., 2018). The STEM content learning dimension examines the accuracy of the content and evidence of youth learning. The inquiry dimension evaluates the degree to which youth are engaged in activities that STEM professionals use in their work. The reflection dimension rates the extent to which youth have opportunities to reflect on their STEM activities and the level of meaningful reflection. Figure 3 depicts the average DoS observation ratings on these three dimensions before and after the Click2Science professional development intervention. To put these values in perspective, data from a larger sample of ratings collected for the DoS observation instrument development and initial psychometric report were included as a comparison in Figure 3 (Shah et al., 2014). For the psychometric report, a total of 284 observations were collected across 58 STEM programs in the Midwest and New England. Shah and colleagues (2014) conducted these observations purely to test the DoS instrument with all scores from all observations used to calculate the mean and standard deviations presented in Figure 3. Participants who experienced the Click2Science professional development intervention improved on all three dimensions of STEM content learning. Prior to participating in the professional development, participants' mean scores on the DoS dimensions of focus were 2.25 ( $S D=0.75$ ) on the STEM content dimension, $2.50(S D=0.80)$ on the inquiry dimension, and $2.17(S D=$ 0.72 ) on the reflection dimension. Following the professional development intervention, participants' mean scores improved to $2.92(S D=0.67)$ on the STEM content dimension, 3.00 $(S D=0.43)$ on the inquiry dimension, and a $2.67(S D=0.78)$ on the reflection dimension. Due to the small sample size (three participants from each location), data were aggregated to protect participants' identities and further emphasize that the DoS observation protocol is intended to reflect overall program quality, not specific facilitator/staff skill level. 
STEM Professional Development

Figure 3. Average DoS Rating in Current Study and From Shah et al. (2014)

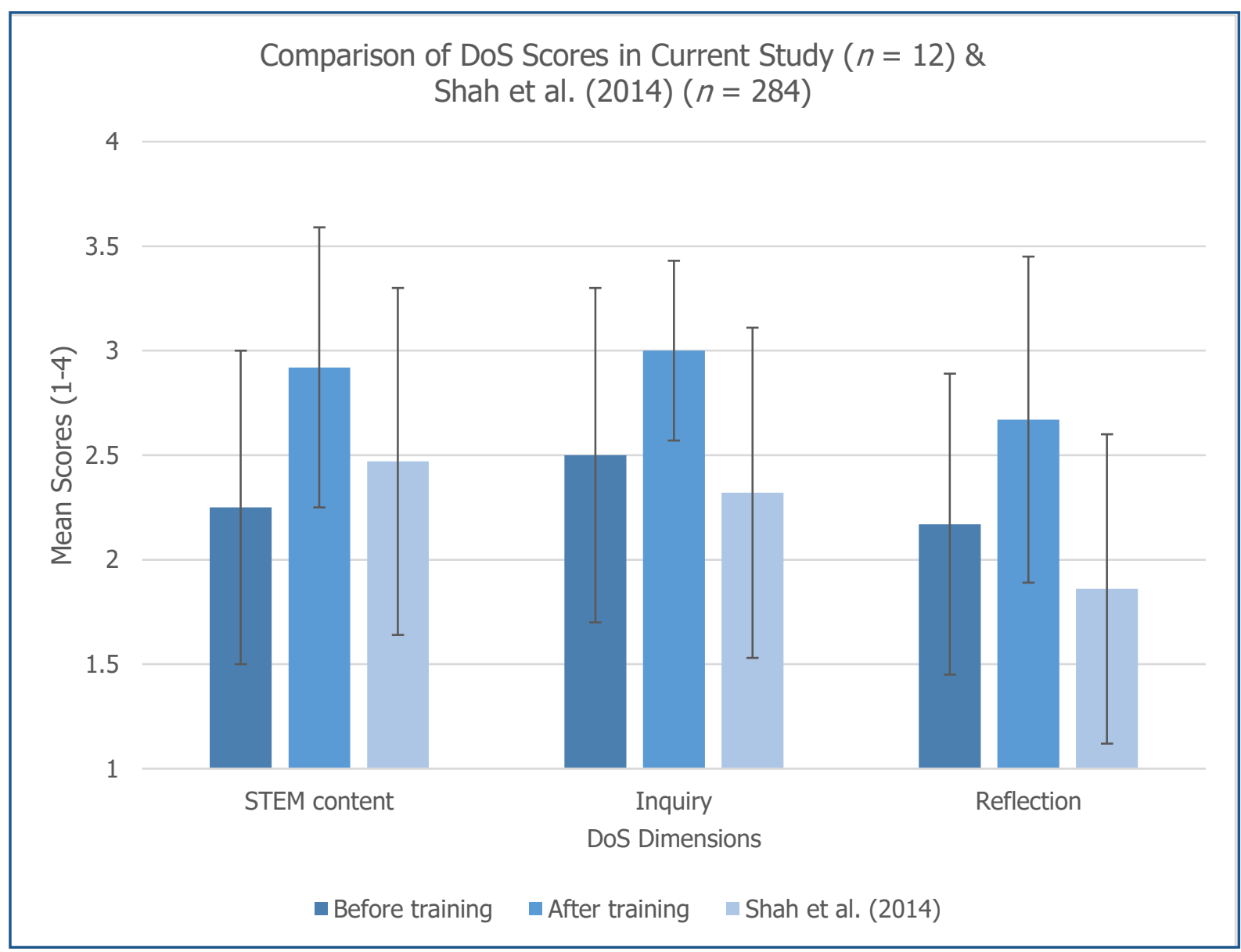

Youth Surveys

Another source of evidence used to support the DoS data was survey data from youth participating in enrichment activities facilitated by the staff members who received the professional development.

\section{Participants}

Youth data were collected in the spring after frontline staff had concluded the majority of their professional development activities. About two weeks prior to data collection, site or program directors/coordinators were emailed a packet that included directions to be read aloud to youth prior to the survey, youth surveys, and parental notification forms so parents could opt youth out of data collection, if desired. 


\section{STEM Professional Development}

Survey data were collected from 239 youth in grades 3-8 involved in OST programs across the four geographic locations. Youth had to be at least in $3^{\text {rd }}$ grade to be included in the data reported in this article. Please note that samples are not fully representative of participants from each location because several locations had large populations younger than $3^{\text {rd }}$ grade. Within our sample, the majority of youth classified themselves as Caucasian $(n=112 ; 46.9 \%)$, males ( $n=127 ; 54 \%)$, in grade $3(n=86 ; 36 \%)$, and participating in their science program once a week $(n=108 ; 46.4 \%)$.

\section{Common Instrument}

The Common Instrument ([CI], n.d.; Allen et al., 2017; Martinez, Linkow, Velez, \& DeLisi, 2014), a self-report survey, was used to measure youths' attitudes, interest, engagement, and career interest in STEM. Permission to use the CI for the purpose of this evaluation was obtained from PEAR. The CI first asks youth to rate how much they agree or disagree with several science-related statements on a 4-point Likert-type scale (10 questions). Next, they were asked to indicate their curiosity level regarding various STEM concepts (four questions). The CI exhibited good reliability $(a=0.86)$ in the current study. As per the permission agreement for $\mathrm{CI}$, only a sample of select items from the instrument are reported (see Table 2).

Table 2. Select Common Instrument Results

\begin{tabular}{|l|l|l|l|}
\hline Common Instrument item & $n$ & Mean & SD \\
\hline I get excited about science. & 237 & 2.97 & 0.83 \\
\hline I like to participate in science projects. & 237 & 3.13 & 0.85 \\
\hline I like to make things. & 232 & 3.31 & 0.85 \\
\hline How curious are you about science? & 234 & 2.88 & 0.93 \\
\hline
\end{tabular}

Note. Response options were scored on a Likert-like scale of 1 (e.g., strongly disagree or not at all curious) to 4 (e.g., strongly agree or extremely curious).

\section{Youth Survey Results}

Across all locations, the majority of youth reported they get excited about science and like to participate in science activities. Youth indicated positive perceptions (i.e., means closer to 4) 


\section{STEM Professional Development}

regarding their general STEM learning experiences and curiosity about general STEM areas. Yet, data indicated some inconsistencies regarding items that asked about interest in a sciencerelated job in the future and curiosity about math and engineering. As a whole, the snapshot of information on youths' perceptions demonstrate youth have positive attitudes towards broad science aspects, but express varying opinions about specific areas of STEM, particularly engineering and mathematics.

The researchers calculated an average score for the participants on the CI and compared that to average scores reported in Martinez et al. (2014). In the evaluation of the NASA Summer of Innovation (SoI) Project, Martinez and colleagues (2014) collected pre and post CI scores using PEAR's 2014 version of the CI and compared the findings with benchmarks using PEAR's Common Instrument Validation (CIV) dataset. The current version of the $\mathrm{CI}$ and the Enthusiasm for Science Scale used in the SoI evaluation share eight common items and were designed to measure interest in and enthusiasm for science. Although the instrument has changed over time, there is enough consistency to allow for comparisons between both the SoI study and the CIV benchmarks reported by Martinez et al. (2014) (see Figure 4). Average scores reported following the cycle of Click2Science professional development were slightly lower than the scores reported for the SoI program (Martinez et al., 2014). However, scores were in line with what is reported in the CIV dataset (Martinez et al., 2014). Youth participants appear to have average interest and attitudes toward STEM.

Figure 4. Comparison of CI Scores With Those Reported in Martinez et al. (2014)

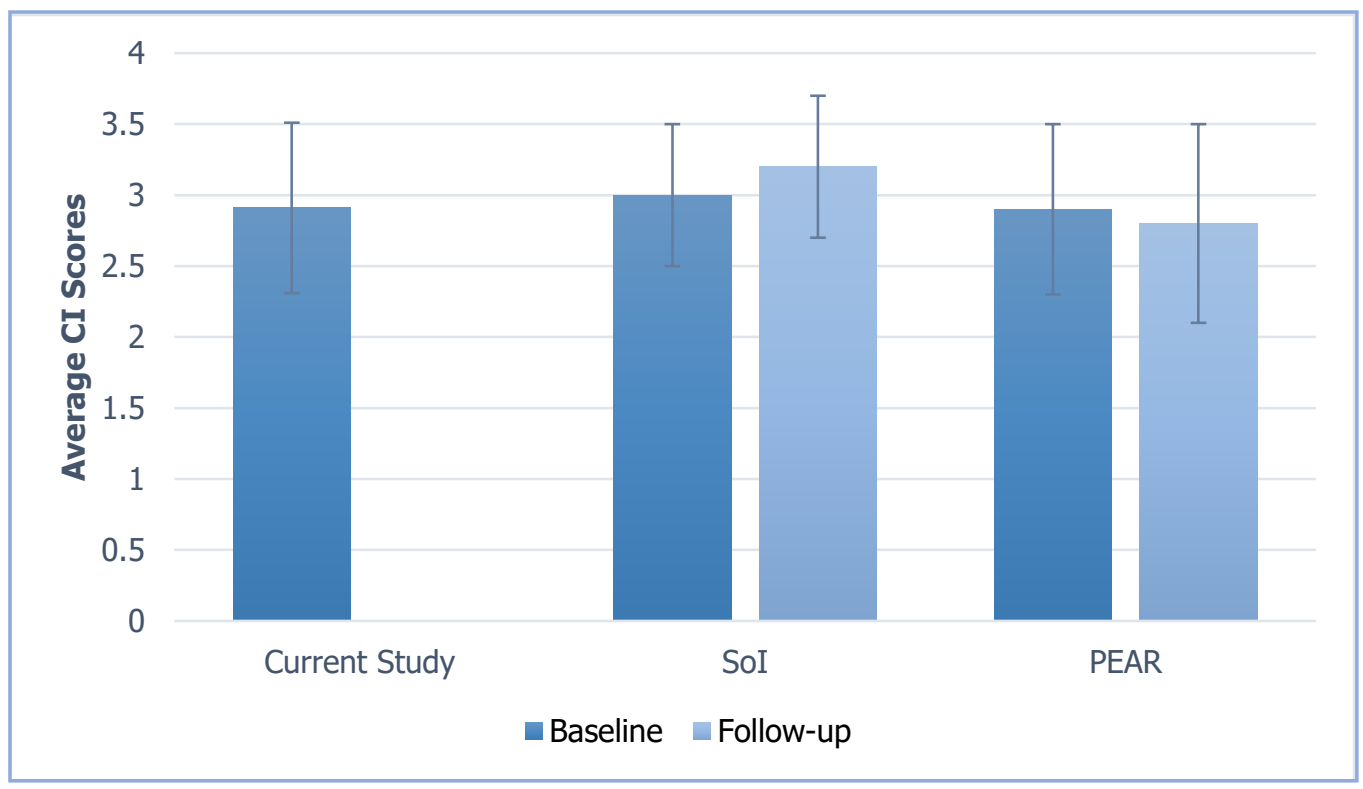




\section{Focus Group/Interviews}

\section{Participants}

Six interviews/focus groups were conducted with 34 individuals ( 5 site or program directors/coordinators and 29 frontline staff) involved in OST programs from multiple sites within the four geographic locations. Participants included site or program directors/coordinators who were responsible for implementing Click2Science professional development and frontline staff who participated in the professional development.

\section{Procedures}

Site or program directors/coordinators, who were responsible for implementing Click2Science professional development, participated in small interview sessions. Frontline staff trained using Click2SciencePD's approach participated in larger focus group discussions. Interviews and focus group sessions lasted from 50 to 70 minutes and discussions were recorded for later analysis. Interviews were transcribed and coded for themes to identify broad, general patterns regarding participants' experiences.

\section{Focus Group/Interview Results}

Participants in the focus groups described their experiences providing (site or program directors/coordinators) or receiving (frontline staff) professional development. Three main themes arose from both groups. These themes included (a) the professional development experience was eye-opening, (b) the resources were engaging and useful, and (c) the skills they learned encouraged youth engagement.

\section{Eye-Opening}

Both frontline staff and site or program directors/coordinators consistently referenced that the professional development materials introduced new ways of thinking and facilitating STEM experiences. This professional development "opened my eyes, gave me more of an insight to what I am giving the kids can be STEM." "It [PD] gives you a different outlook...taught me to present things more like solving a problem. It was much different, the approach was much different."

The professional development "helped me with my approach and how I approach the little ones....keeping them involved...asking questions...listening." Participants admitted to being 


\section{STEM Professional Development}

surprised by how much they enjoyed the experiences and the things they learned. "I thought it was going to be a boring day, just another training." "It [training] was fun and we learned a lot [about STEM]."

\section{Utility}

Site or program directors/coordinators and frontline staff highlighted several aspects of Click2Science professional development they found to be useful in meeting their professional development needs. These site or program directors/coordinators shared several positive observations about their experiences training staff using the Click2SciencePD materials and professional development approach. "For me as a facilitator, it [Click2SciencePD] gave me the tools to correctly facilitate STEM."

So many times staff take a training and it's the theory of STEM...I felt [the PD] provided them [staff] with the actual skills of this is how you ask purposeful questions or this is an example of someone in a tinker room asking purposeful questions.

Frontline staff who participated in the professional development also had several positive comments on their experiences. "[The PD] has been really cool, I like the activities and they are more hands-on and engaging."

In the training I've been able to take back things like purposeful questions, making sure I'm hands-on with a group, and also allowing the kids to feel like they know how to be in certain roles, like they can be in leadership roles.

Several participants highlighted the utility of the videos for providing a deeper learning opportunity. "The videos got me excited... finding different ways and thinking about what way would work best for us and how to interest the kids." All participants felt the selfdirected, web lessons were "very user-friendly," "convenient, and straightforward."

\section{Youth Engagement}

Several of the frontline staff participants commented on the link between the skills they learned in their professional development experiences and youths' engagement. "[The PD] has helped me get them [the youth] more engaged . . . not excited yet, just interested and more curious about it [STEM]." Multiple individuals felt the tools they picked up in the professional development would help them "take a lot of the fear out of science and engineering and math 


\section{STEM Professional Development}

and technology." "They [youth] don't know sometimes how much they are learning but they are because they are doing all these hands-on things [from the PD training] that are actually science and math...it takes the fear out of those words."

As a whole, participants noted the activities introduced through the professional development experiences were generally well received by youth. "The kids really got behind them [PD activities] more than some of the other STEM activities we have done in the past...they dug the sandwich one we did." "It [PD activities] is going to challenge the kids in areas that they have never thought of before." A site or program director/coordinator also commented that the professional development was making a positive impact on youth in ways that their program had not yet been able to achieve.

\section{Discussion}

The purpose of this study was to evaluate the impact of the Click2Science professional development approach and materials. Our results were promising in that even with a small sample of sites and participants, we found evidence of higher quality STEM learning experiences following professional development focused on pedagogical approaches staff can implement in their practice. Although we focus on the DoS domain, STEM knowledge and practices, collective DoS scores on all dimensions either remained stable or increased following the Click2Science intervention. This is consistent with Vandell and colleagues (2016) findings that professional development contributed to increased quality of the STEM activities implemented by staff.

The promising evidence found from the observations of frontline staff was also supported by other data sources. Youth survey results and interviews with frontline staff and site or program directors/coordinators indicated positive perceptions of STEM learning experiences. In terms of youth, research indicates that personal interest and enthusiasm are important factors for youth participation in learning science (Jolly, Campbell, \& Perlman, 2004). Our data suggests that youth are generally enjoying the OST learning experiences (as demonstrated by CI indicators of engagement and excitement) provided by staff trained in the Click2Science intervention. The youth survey scores were consistent with averages reported by youth participants in a NASA program (Martinez et al., 2014). Focus group interviews with frontline staff and site or program directors/coordinators illustrated how the professional development experiences introduced new ways of thinking about STEM to staff and introduced effective strategies for facilitating STEM learning. These are specific needs outlined as important for improving the quality of STEM programs in OST (NRC, 2015). Effective STEM professional development provides opportunities 


\section{STEM Professional Development}

for staff to learn about STEM disciplinary practices, in addition to age-appropriate youth development and teaching strategies (NRC, 2015). Triangulating all three data sources, the evidence supports that ongoing, professional development in OST programs can enhance staff performance, program quality, and outcomes for youth.

Although the results are promising, the authors recognize there are limitations to this study. The number of staff who participated in pre-post observations is very small $(n=12)$ limiting the generalizability of these results. The youth data was collected following the implementation of the Click2Science professional development approach; thus pre-post comparisons cannot be made to draw conclusions about the impact STEM professional development has on youth interest and excitement in STEM.

Future research is needed to test the efficacy of this professional development approach (Figure 1) and analyze the impact of variations on the recommended cycle. Evaluating the ongoing, blended approach with additional sources of data from youth workers (e.g., lesson plans and self-confidence assessments) would bolster conclusions drawn about the improvement in staff's practices, both in planning and facilitating STEM learning experiences. Conducting a randomized controlled trial would allow for causal inferences in program efficacy to be made, as well. Collecting pre-post youth impact data or school achievement data is needed to draw conclusions about how the improvement in staff practices are impacting youth learning outcomes.

\section{Conclusions}

In the current study, the Click2Science professional development approach and resources appeared to improve STEM program quality. Program staff found the resources engaging and easy to use. This study reinforces the need for ongoing professional development opportunities for OST program staff. Experts in OST have consistently pointed to staff capacity as the key to high-quality OST programs (Davis, Lingo, \& Woodruff, 2013; Larson, Rickman, Gibbons \& Walker, 2009; Little, 2004; Mahoney \& Warner, 2014). Investing in STEM-focused professional development has the potential to improve the quality of STEM learning experiences in OST (NRC, 2015). Supporting findings in previous formal and informal educational literature, this study recommends that professional development (a) occur over a sustained period of time, (b) include different types of learning activities, (c) include follow-up experiences, (d) include the collective staff at the site, and (e) include opportunities to practice what is learned during STEM programming. The professional development model and resources from Click2Science offers a 


\section{STEM Professional Development}

promising approach to improving OST program quality by incorporating high-quality, STEM professional development in a low-cost, flexible way. Further research is needed to extend the preliminary findings and support the case for increased investment in STEM professional development for youth development professionals. Future research can help OST programs understand how STEM professional development affects program quality and how improving program quality affects youth in OST programs.

\section{References}

Afterschool Alliance. (2010). Issue Brief No. 44 Afterschool: Middle school and science, technology, engineering and math (STEM), 1-7. Retrieved from_http://www.afterschoolalliance.org /issue_briefs/issue_stem_44.pdf

Afterschool Alliance (2014). America after 3PM: Afterschool programs in demand. Retrieved from http://www.afterschoolalliance.org/documents/AA3PM-2014/AA3PM_National_Report.pdf.

Afterschool Alliance (2015). America after 3PM: Full STEM ahead. Retrieved from http://www.afterschoolalliance.org/AA3PM/STEM.pdf.

Allen, P. J., Noam, G. G., Little, T. D., Fukuda, E., Gorrall, B. K., \& Waggenspack, B. A. (2017). Afterschool \& STEM system building evaluation 2016. Retrieved from https://docs.wixstatic.com/ugd/e45463_e14ee6fac98d405e950c66fe28de9bf8.pdf

Birman, B. F., Desimone, L., Porter, A. C., \& Garet, M. S. (2000). Designing professional development that works. Educational Leadership, 578), 28-33.

Chun, K., \& Harris, E. (2011). STEM out-of-school time programs for girls. Harvard Family Research Project Research Update, 5, 1-8. Retrieved from https://globalfrp.org/Archive

Common Instrument Suite (n.d.). Common Instrument Suite. Retrieved from https://www.thepearinstitute.org/common-instrument-suite

Davis, J., Lingo, L., \& Woodruff, S. (2013). Strategies used to improve Florida's $21^{\text {st }}$ century community learning centers. In T. Peterson (Ed.), Expanding minds and opportunities: Leveraging the power of afterschool and summer learning for student success (pp. 67-73). Washington DC: Collaborative Communications.

Fayer, S., Lacey, A., \& Watson, A. (2017). STEM occupations: Past, present, and future. Retrieved from U.S. Bureau of Labor and Statistics website: https://www.bls.gov/spotlight/2017/sciencetechnology-engineering-and-mathematics-stem-occupations-past-present-and-future/pdf/sciencetechnology-engineering-and-mathematics-stem-occupations-past-present-and-future.pdf

Freeman, J., Dorph, R., \& Chi, B. (2009). Strengthening after-school STEM staff development (pp. 1-34). Retrieved from Coalition for Science After School website: http://www.informalscience.org/sites/ 


\section{STEM Professional Development}

default/files/Strengthening_After-School_STEM_Staff_Development.pdf

Frerichs, S. W., Fenton, M. P., \& Wingert, K. (2018). A model for out-of-school educator professional learning. Adult Learning, 29(3), 115-122. doi:10.1177/1045159518773908

Furtak, E. M., Seidel, T., Iverson, H., \& Briggs, D. C. (2012). Experimental and quasi-experimental studies of inquiry-based science teaching: A meta-analysis. Review of Educational Research, 82(3), 300329. doi:10.3102/0034654312457206

Garet, M. S., Porter, A. C., Desimone, L., Birman, B. F., \& Yoon, K. S. (2001). What makes professional development effective? Results from a national sample of teachers. American Education Research Journal, 38(4), 915-945. doi:10.3102/00028312038004915

Guskey, T. R., \& Yoon, K. S. (2009). What works in professional development? Phi Delta Kappan, 90(7), 495-500.

Huang, D., \& Cho, J. (2010). Using professional development to enhance staff retention. Afterschool Matters, 12, 9-16.

Jolly, E., Campbell, P., \& Perlam, L. (2004) Engagement, capacity, continuity: A trilogy for student success. Retrieved from http://www.campbell-kibler.com/trilogy.pdf

Larson, R. W., Rickman, A. N., Gibbons, C. M., \& Walker, K. C. (2009). Practitioner expertise: Creating quality within the daily tumble of events in youth settings. New Directions for Youth Development, 2009(121), 71-88. doi:10.1002/yd.297

Little, P. M. (2004). A recipe for quality out-of-school time programs. The Evaluation Exchange, 10(1), 18-19.

Krishnamurthi, A., \& Bevan, B. (2017). From evidence to policy: The case for STEM in afterschool. Retrieved from STEM ready America website: http://stemreadyamerica.org/wp-content/ uploads/2017/02/STEM-Ready_Articles_Bevan.pdf

Krishnamurthi, A., \& Sankar, R. (2012, July-August). STEM learning in afterschool: Ready to soar. Dimensions, 38-39. Retrieved from: http://www.astc.org/DimensionsPDFS/2012/JulAug.pdf

Mahoney, J. L., \& Warner, G. (2014). Issue editors' notes. New Directions for Youth Development, 2014(144), 1-10. doi:10.1002.yd.20108

Martinez, A., Linkow, T., Velez, M., \& DeLisi, J. (2014). Evaluation study of Summer of Innovation standalone program model (FY 2013: Outcomes report). Retrieved from National Aeronautics and Space Administration (NASA) website: https://www.nasa.gov/sites/default/files/soi_standalone_program_model_fy2013_outcome_report.pdf

National Research Council. (2012). A framework for $K$-12 science education: Practices, crosscutting concepts, and core ideas. Washington, D.C: The National Academies Press.

National Research Council. (2015). Identifying and supporting productive STEM programs in out-of-school settings. Washington DC: National Academies Press. 


\section{STEM Professional Development}

Nee, J., Howe, P., Schmidt, C., \& Cole, P. (2006). Understanding the afterschool workforce: Opportunities and challenges for an emerging profession. Houston, TX: National Afterschool Association for Cornerstones for Kids.

PEAR Institute. (n.d.). DoS Observation Tool. Retrieved from https://www.thepearinstitute.org/dosobservation-tool

Shah, A. M., Wylie, C. E., Gitomer, D., \& Noam, G. (2014). Development of the Dimensions of Success (DoS) observational tool for the out of school time STEM field: Refinement, field-testing and establishment of psychometric properties. Belmont, MA: Program in Education, Afterschool \& Resiliency, Harvard University and McLean Hospital.

Shah, A. M., Wylie, C. E., Gitomer, D., \& Noam, G. (2018). Improving STEM program quality in out-ofschool-time: Tool development and validation. Science Education, 102(2), 238-259. doi:10.1002/sce.21327

Vandell, D. L., Simzar, R., O'Cadiz, P., \& Hall, V. (2016). Findings from an afterschool STEM learning initiative: Links to professional development and quality STEM learning experiences. The Journal of Expanded Learning Opportunities, 1(3), 7-26.

Walker, G., Wahl, E., \& Rivas, L. M. (2005). NASA and afterschool programs: Connecting to the future. New York, NY: American Museum of Natural History.

Yohalem, N., \& Pittman, K. (2006). Putting youth work on the map. Washington DC: Forum for Youth Investment.

Yohalem, N., Pittman, K., \& Edwards, S. L. (2010). Strengthening the youth development/after-school workforce: Lessons learned and implications for funders. Washington DC: The Forum for Youth Investment. Retrieved from https://youtheconomicopportunities.org/sites/default/files/uploads /resource/Strengthening_the_YD-AS_Workforce.pdf 